\title{
Paradigm of Bone Marrow Metastasis in Retinoblastoma
}

\author{
Shahzad Ali Jiskani ${ }^{*}$, Samina Amanat ${ }^{2}$, Lubna Naseem ${ }^{1}$, Sundas Ali², Aliena Sohail ${ }^{1}$, Asfa Zawar ${ }^{1}$ \\ ${ }^{1}$ Department of Pathology, Pakistan Institute of Medical Sciences, Islamabad, Pakistan. \\ ${ }^{2}$ Department of Pathology, Pakistan Atomic Energy Commission, General Hospital, Pakistan.
}

\begin{abstract}
Introduction: Retinoblastoma is most common pediatric ocular malignancy. Majority of patients presented with unilateral disease. Infiltration to other organs is common with bone marrow being one of the most common organ involved.

Methodology: This study was conducted at Pakistan Institute of Medical Sciences Islamabad for a period of one year. A total of 47 known patients of retinoblastoma were included in study. All patients underwent bone marrow biopsy for evaluation of infiltration.
\end{abstract}

Results: Out of 47 patients, 32 (68.1\%) were male and 15 (31.9\%) were female (ratio 2.13:1). 37 (78.7\%) patients were unilateral and 10 $(21.3 \%)$ were bilateral. Bone marrow infiltration was present in $14(29.78 \%)$ cases.

Conclusion: Bone marrow is among most common sites of involvement in patients with bone marrow biopsy. Distant metastatic involvement has great impact on treatment and overall survival of patients.

Keywords: Retinoblastoma, Bone marrow, Metastasis, Malignancy, RB gene, Malignancy, Ocular.

\section{INTRODUCTION}

Retinoblastoma is among most common ocular malignancy in pediatric age group. It is responsible for about $1 \%$ of deaths from cancer in patients up to 15 years of age $[1,2]$. In $60 \%$ patients, retinoblastoma is unilateral and $40 \%$ were bilateral [3]. "Two - hit" model was described two events for conversion of retinal cells into malignant cells. The mutation causing the event is inherited and is more likely to be present in all cells of the body. The second 'hit' event usually results in loss of remaining normal allele and takes place within specific cells in the retina or cells with dysregulation of cell cycle and ultimately inadequate entry in $S$ phase [4]. Retinoblastoma usually presents as leukocoria or strabismus. In the later stage of retinoblastoma, it may present as hypopyon, proptosis or buphthalmos. The main pathological genetic problem is loss of function mutation in $R B 1$ gene on chromosome $13 \mathrm{q}[5,6]$. $R B 1$ gene functions as tumor suppressor gene which is essential for adequate cell cycle exist in progenitor cells in retina which are proliferating. It is also required for adequate maturation in differentiation of rods. If $R B 1$ gene is absent, the progenitor cells will be divided continuously and maturation of the rods will not take place $[7,8]$. Retinoblastoma is associated with an increased risk of secondary tumors. Metastasis to various organs e.g. bone marrow is associated with retinoblastoma and it is related to various ocular, pathological and outcome factors in treatment $[9,10]$.

Bone marrow is one the commonest site which is involved in

*Address correspondence to this author at the Department of Pathology, Pakistan Institute of Medical Sciences, Islamabad, Pakistan.

E-mail: shahzadbaloach289@gmail.com metastasis and its detection is of great importance for staging of tumor spread. Metastasis influences the response treatment response, survival and reduced hematopoiesis [11]. In this study, we evaluated the frequency of bone marrow infiltration in patients with retinoblastoma.

\section{MATERIALS AND METHODS}

This was a cross-sectional study, conducted at Department of Pathology, Pakistan Institute of Medical Sciences for the period of one year (January 2016 to December 2016). A total of 47 pediatric patients who were known cases of Retinoblastoma were included in the study. After full consent, all patients underwent bone marrow biopsy for staging of the disease. Patients on chemotherapy/radiotherapy were excluded from the study. All basic hematological markers (e.g. CBC, Retics) were evaluated in the patients. Bone marrow aspiration was performed on patients from tibia (for patients less than 2 years) and posterior iliac crest (for patients more than 2 years), under local anesthesia. Aspiration was performed using 16G LP needle and trephine was performed using $14 \mathrm{~g}$ x $40 \mathrm{~mm}$ trephine biopsy needle. Slides were prepared using May - Grunwaled - Giemsa stain and examined for presence of malignant cells. Data was analyzed using statistical software SPSS version 21. Quantitative variables like age and other hematological markers are presented as mean \pm standard deviation. Qualitative variable like gender, restinoblastoma type and results of bone marrow biopsy are expressed as frequencies with percentages.

\section{RESULTS}

A total of 47 patients were selected for the study. Out of 47 patients, $32(68.1 \%)$ were male and 15 (31.9\%) were female. 
Male to female ratio was 2.13:1 (Fig. 1). Age of patients was ranged from 6 months to 11 years and the mean age was $6.1 \pm$ 1.86 years. $37(78.7 \%)$ cases were unilateral and $10(21.3 \%)$ were bilateral (Fig. 2). Infiltration was present in $14(29.78 \%)$ cases, while $33(70.21 \%)$ did not show any tumor cells. Hemophagocytosis was present in $15(31.9 \%)$ cases. 20 cases (42.6\%) showed increased lymphocytes on bone marrow (Fig. 3). Basic hematological parameters were evaluated by $\mathrm{CBC}$ and reticulocyte count. Mean hemoglobin was $10.36 \pm 1.53$ $\mathrm{g} / \mathrm{dL}$, mean MCV was $69.64 \pm 7.45 \mathrm{fL}$, mean RBC count was $4.46 \pm 0.76$ millions, mean hematocrit was $33.3 \pm 3.33 \%$, mean WBC count was $13.55 \pm 4.18 \times 109 / \mathrm{L}$, mean RDW $17.81 \pm 2.47 \%$, mean platelet count $484.61 \pm 119.30 \times 109 / \mathrm{L}$, mean neutrophil count $45.70 \pm 13.55 \pm$, mean lymphocyte count $44.74 \pm 13.55 \%$, mean monocyte count $4.53 \pm 2.96 \%$, mean eosinophil count $4.97 \pm 4.3 \%$ and mean reticulocyte count $1.28 \pm 0.84 \%$ (Table 1).

Table 1. Hematological Parameters in Patients with Retinoblastoma $(\mathrm{n}=47)$.

\begin{tabular}{|l|l|}
\hline & Mean \pm Standard Deviation \\
\hline Age (years) & $6.1 \pm 1.86$ \\
\hline Hemoglobin (g/dL) & $10.36 \pm 1.53$ \\
\hline MCV (fL) & $69.64 \pm 7.45$ \\
\hline RBC (millions) & $4.46 \pm 0.74$ \\
\hline HCT (\%) & $33.30 \pm 3.33$ \\
\hline WBC (x 103/L) & $13.55 \pm 4.18$ \\
\hline Platelets (x 109/L) & $484.61 \pm 119.30$ \\
\hline RDW (\%) & $17.81 \pm 2.47$ \\
\hline Neutrophils (\%) & $45.70 \pm 13.68$ \\
\hline Lymphocytes (\%) & $44.74 \pm 13.55$ \\
\hline Monocytes (\%) & $4.53 \pm 2.96$ \\
\hline Eosinophils (\%) & $4.97 \pm 4.30$ \\
\hline Retics (\%) & $1.28 \pm 0.844$ \\
\hline
\end{tabular}

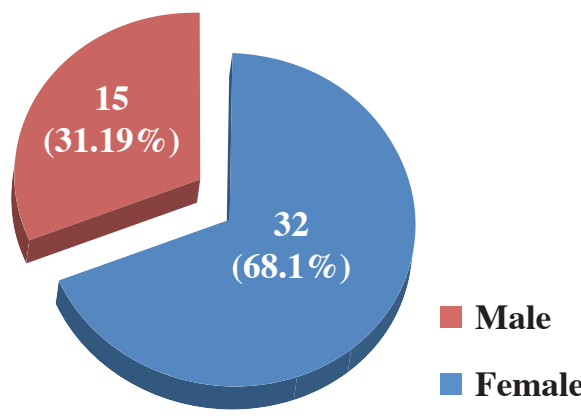

Fig. (1). Gender Distribution ( $\mathrm{n}=47)$.

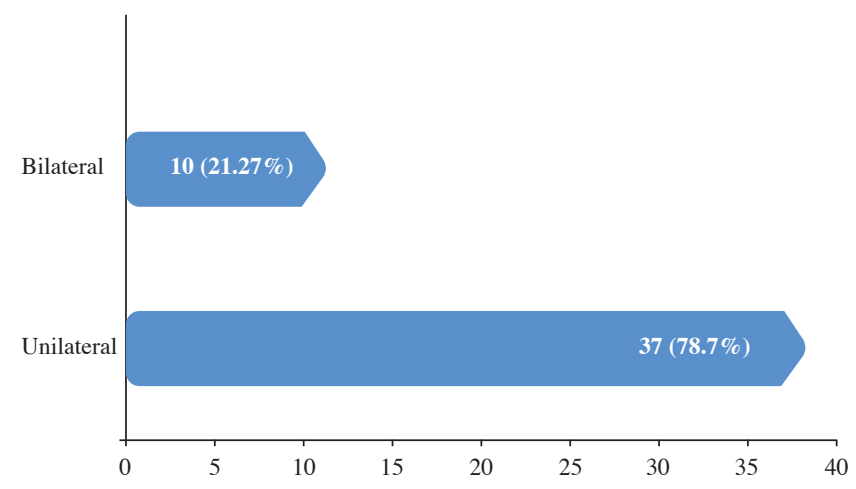

Fig. (2). Type of Retinoblastoma $(n=47)$.

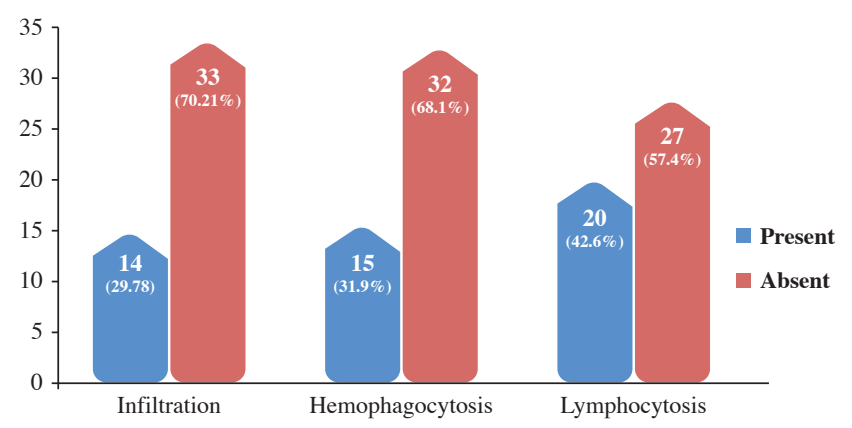

Fig. (3). Bone Marrow Biopsy Examination in Patients with Retinoblasstoma $(\mathrm{n}=47)$.

\section{DISCUSSION}

Retinoblastoma is among most common intraocular tumor of childhood. It makes up approximately $4 \%$ of all childhood malignancies [12]. Bone marrow is a common site for secondary involvement in patients with retinoblastoma, followed by bones, liver, and other organs [13]. Various studies have been done to see the paradigm of infiltration in retinoblastoma. Khurram et al performed a study in 2011 . He showed that $41.2 \%$ patients were bilateral, and $62.74 \%$ patients presented with advanced stage disease [14]. These result are different from our study, in which majority of patients were unilateral and presented in primary stage. Arif et al presented a study in Peshawar. He included 80 known cases of Retinoblastoma. In his study $25 \%$ patients presented with metastasis [15]. Khurshid et al. performed a study in patients with retinoblastoma. He showed that $90 \%$ patients had unilateral disease, and $10 \%$ patients presented with bone marrow infiltration [16]. Hu et al. showed his study on 24 patients with retinoblastoma. In his study $75 \%$ were unilateral, but only 1 case $(4.16 \%)$ showed bone marrow infiltration [17]. Zhang et al. did a study on 92 patients with retinoblastoma, with $83.69 \%$ patients presented with unilateral retinoblastoma[ 18]. Selistre et al. showed the data of patients of retinoblastoma in Brazil. He included 140 patients in his study, out of which $65 \%$ patients were unilater- 
al, and $10.7 \%$ patients showed metastatic infiltration at various sites [19]. Majority of studies were in favor of our study with majority of patients having unilateral disease. Bone marrow biopsy is one of the common sites involved in patients with retinoblastoma, having significant impact of treatment and overall survival [20]. Hematological parameters, especially hemoglobin level and MCV decreased. This may be explained by role of RB gene involved in the process of erythropoiesis, which may include the role of retinoblastoma protein - interacting zinc finger protein (RIZ)/ positive regulatory domain methyl transferase (PRDM2) having tumor - suppressive properties. Deletion of loss of heterozygosity of this gene is present in various human malignancies, including both hematological and malignant lymphoma [3].

\section{CONCLUSION}

Majority of patients presented with unilateral retinoblastoma with significant number of patients having bone marrow infiltration. Early detection of metastatic involvement may be beneficial in treatment modalities. With proper and early investigation in patients with retinoblastoma, disease can be diagnosed before involvement of other organs.

\section{CONFLICT OF INTEREST}

Declared none.

\section{ACKNOWLEDGEMENTS}

Declared none.

\section{REFERENCES}

[1] Khurshid I, Naeem S, Bashir F, et al. Retinoblastoma; Bone marrow infiltration - A study of 30 cases. Annals 2004; 10(2): 194-6. DOI: 10.21649/akemu.v10i2.1205

[2] Wilson WG. Retinoblastoma. Pediatr Rev 2017; 28(1): 37-8. DOI: $10.1542 /$ pir.28-1-37

[3] Rouic L. Retinoblastoma update. Arch Pediatr 2016; 23(1): 112-6.

[4] Murali C, Barrios PC, Paysse EA, et al. Retinoblastoma: Review of current management. Oncologist 2007; 12: 1237-46. DOI: 10.1634/theoncologist.12-10-1237

[5] Hungerford JL, Kingston JE, Onadim Z. Spectrum of RB1 mutations identified in 403 retinoblastoma patients. J Med Genet 2017; 51(3): 3-5.

[6] Garcia-Chequer AMT, Ruiz GO, Vallejo CS, Isa P, Arias C, Torres J. Overview of recurrent chromosomal losses in retinoblastoma detected by low coverage next generation sequencing. Cancer Genet 2016; 209(3): 57-69.

DOI: $10.1016 /$ j.cancergen.2015.12.001
[7] Mehta M, Sethi S, Pushker N et al. Retinoblastoma. Singapore Med J 2012; 53(2): 128-35.

[8] Dimaras H. Retinoblastoma genetics in India: From research to implementation. Indian J Ophthalmol 2017; 63(3): 219-26. DOI: $10.4103 / 0301-4738.156917$

[9] August CO, Khosravi A, Shahrabi S et al. The bone marrow metastasis niche in retinoblastoma. Cell Oncol 2015; 38(4): 253-63. DOI: 10.1007/s13402-015-0232-x

[10] Wang A, Hsu W, Hsia W, Liu J, Yen M. Clinicopathologic factors related to metastasis in retinoblastoma. J Pediatr Ophthalmon Strabismus 2001; 38(3): 166-71.

[11] Brahmbhatt B, Parikh B, Shah M. Bone marrow involvement by metastatic solid tumors. Gujrat Med J 2017; 69(2): 54-7.

[12] Meel R, Radhakrishnan V, Bakhshi S. Current therapy and recent advances in the management of retinoblastoma. Indian J Paediatr Oncol 2012; 33(2): 80-8.

DOI: $10.4103 / 0971-5851.99731$

[13] Torbidoni A V, Laurent VE, Sampor C, et al. Association of cone-rod homeobox transcription factor messenger rna with pediatric metastatic retinoblastoma. JAMA Ophthalmol 2017; 133(7): 805-12. DOI: 10.1001/jamaophthalmol.2015.0900

[14] Darakhshanda K, Naima Z, Shadab H. Clinical presentation and staging of newly diagnosed intraocular retinoblastoma according to international classification of retinoblastoma. Al-Shifa J Ophthalmol 2011; 7(1): 32-8.

[15] Muhammad A, Zafar I, Ziaul I. Retinoblastoma presenting as metastasis. J Ayub Med Coll Abottabad 2010; 22(1): 109-11.

[16] Irfan K, Samina N, Faiza B, Ayyaz L, Noman A, Abdul H. Retinoblastoma; bone marrow infiltration - A study of 30 cases. Ann King Edward Med Uni 2004; 10(2): 194-6.

[17] $\mathrm{Hu} \mathrm{H}$, Zhang W, Wang Y, et al. Clinical features, treatment and prognosis of retinoblastoma in distant metastasis stage. Zhonghua Yan Ke Za Khi 2017; 53(2): 121-7.

[18] Zhang Y, Zhang WL, Wang YZ, et al. The clinical characteristics and prognosis of 92 cases of delayed occurrence of retinoblastoma. Zhonghua Yan Ke Za Khi 2013; 49(9): 812-6.

[19] Selistre SGA, Maestri MK, Santos-silva P, et al. Retinoblastoma in a pediatric oncology reference center in Southern Brazil. BMC Pediatr 2016; 16: 1-9.

DOI: $10.1186 / \mathrm{s} 12887-016-0579-9$

[20] Temming P, Lohmann D, Bornfeld N, Sauerwein W, Goericke SL. Current Concepts for diagnosis and treatment of retinoblastoma in germany: aiming for safe tumor control and vision preservation. Klin Padiatr 2017; 224(6): 339-47.

DOI: $10.1055 / \mathrm{s}-0032-1327563$ 